Prior to definitive diagnosis, electrodiagnostic studies are often requested in patients with polymyalgia rheumatica to evaluate complaints of muscle aching, tenderness, and weakness. These studies are generally normal, although rare reports of electromyographic abnormalities in polymyalgia rheumatica exist. Two patients with polymyalgia rheumatica and electrodiagnostic findings consistent with diffuse denervation are described. Following steroid treatment, both patients experienced impressive clinical and electromyographic improvement. To explain this improvement, we hypothesize a steroid-responsive microvascular arteritis resulting in ischemic damage to axons of motor nerve terminal branches.

Key words: polymyalgia rheumatica $\bullet E M G \bullet$ steroid-responsive.

MUSCLE \& NERVE 13:138-141

\title{
STEROID-RESPONSIVE ELECTROMYOGRAPHIC ABNORMALITIES IN POLYMYALGIA RHEUMATICA
}

\author{
MARK B. BROMBERG, MD, PhD, PETER D. DONOFRIO, MD, \\ and BARBARA M. SEGAL, MD
}

Polymyalgia rheumatica is distinguished by symptoms of muscle stiffness, aching, and tenderness, with subjective weakness in elderly patients. Physical examination may only show decreased range of motion in shoulder and hip joints. Electrodiag. nostic studies are usually normal, yet abnormalities consistent with either a mild myopathic or neurogenic process have been reported. ${ }^{3,6,9,11}$ We report two patients with polymyalgia rheumatica whose initial electromyographic findings suggested disease of the lower motor neuron. Steroid

From the Departments of Neurology (Drs. Bromberg and Donofrio) and Internal Medicine (Dr. Segal), The University of Michigan Medical Center. Ann Arbor, Ml.

Acknowledgments: The authors thank Venkata Challa, M.D. for assistance in muscle histology interpretation and Sandy Jolly, Pamela Wilson. and Thelma Jordan for manuscript preparation.

Dr. Donofrio's current address is the Department of Neurology, The Bow man Gray School of Medicine, 300 South Hawthorne Road, Winston-Salem, North Carolina, 27103

Dr. Segal's current address is the Department of Internal Medicine, Division of Rheumatology, Henry Ford Hospital, Detroit, MI 48126.

Presented in part at the 34th Annual Meeting of the American Association of Electromyography and Electrodiagnosis, San Antonio, TX, 14-17 October 1987

Address correspondence and reprint requests to Dr. Bromberg at the Department of Neurology, University of Michigan Medical Center, 1500 East Medical Center Drive, 1C325/0032 UH, Ann Arbor, Ml 48109-0032

Accepted for publication November 22, 1988

0148-639X/90/020138-04 \$04.00

(c) 1990 John Wiley \& Sons, Inc. therapy resulted in both clinical and electrodiagnostic improvement. Follow-up examination in both patients disclosed no progression to myopathic or neuropathic disease.

\section{Case pResentation}

JC is a 65-year-old man with progressive shoulder and hip girdle pain and stiffness of 9 months duration. Initial evaluation was remarkable only for Westergren sedimentation rate (WSR) of $100 \mathrm{~mm} /$ hr (normal 0-20), biopsy of the vastus lateralis showing rare angular fibers (Fig. 1), and diffuse electromyographic abnormalities interpreted as motor neuron disease.

At subsequent evaluation, he described an aching discomfort and stiffness in girdle muscles exacerbated by movement and precluding normal activities. He denied headache, visual changes, scalp tenderness, or jaw claudication. A diffuse erythematous rash was observed over the chest. No joint tenderness or effusions were noted, but movement was markedly restricted. There was marked bilateral shoulder girdle muscle atrophy with occasional fasciculations. Strength was normal except for compromised voluntary effort secondary to painful shoulder joints.

Laboratory studies showed slight microcytic anemia, slight elevation of alkaline phosphatase, and WSR of $112 \mathrm{~mm} / \mathrm{hr}$. Temporal artery biopsy identified giant cell arteritis. Electrodiagnostic 


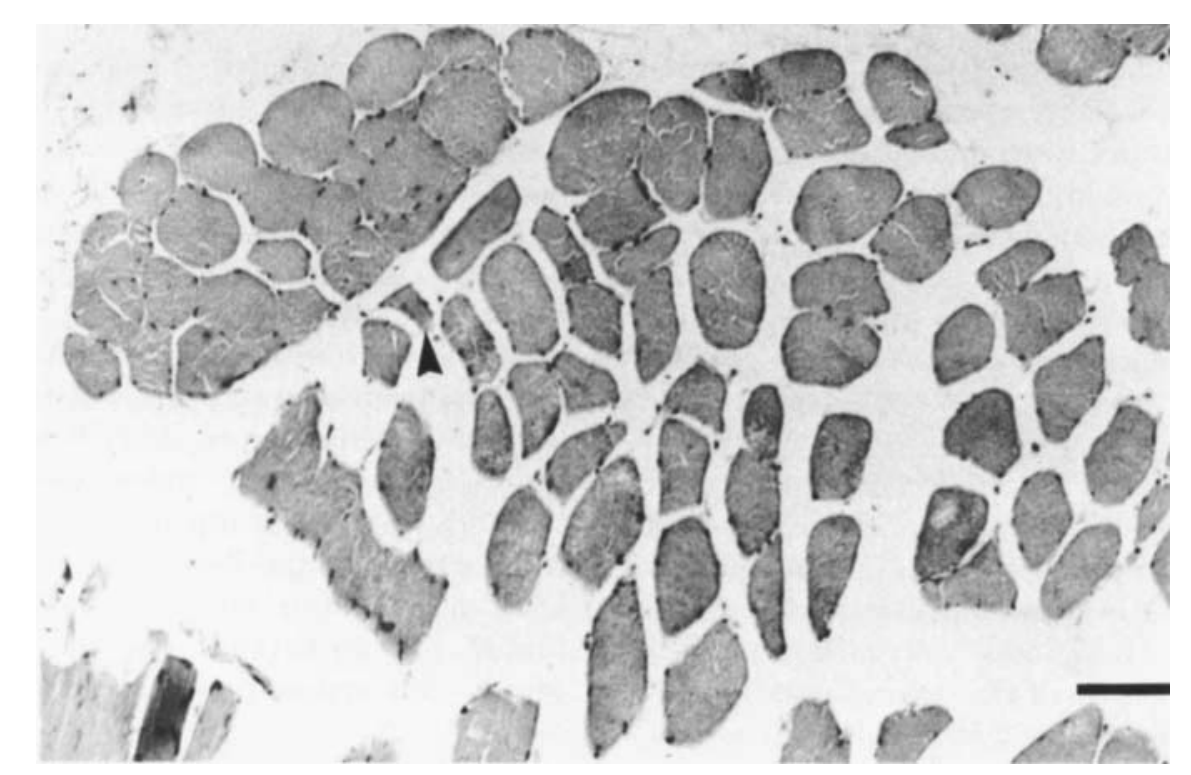

FIGURE 1. Vastus lateralis muscle biopsy. Tissue fixed in formalin, embedded in paraffin, and stained with hematoxylin and eosin. Most fibers are normal; example of rare angular fibers marked by arrowhead. Bar $=100 \mu \mathrm{m}$.

studies showed normal nerve conduction and neuromuscular junction transmission. Concentric needle examination disclosed sustained positive waves and fibrillation potentials in all muscles and complex repetitive discharges in axial and proximal limb muscles (Table 1). On voluntary recruitment with good effort, reduced numbers of motor units with increased amplitude and polyphasja were recorded in all muscles.
Following 2 days of low dose oral prednisone administration ( $5 \mathrm{mg} /$ day) the patient experienced a dramatic resolution of symptoms of stiffness and impaired range of motion. Because of the discovery of temporal arteritis, prednisone was increased to $40 \mathrm{mg} /$ day and slowly tapered over 6 months. At a dose of $5 \mathrm{mg} /$ day, symptoms of polymyalgia rheumatica returned accompanied by a rise in WSR to $45 \mathrm{~mm} / \mathrm{hr}$. Prompt resolution of

\begin{tabular}{|c|c|c|c|c|c|c|}
\hline \multirow[b]{3}{*}{ Parameter } & \multicolumn{4}{|c|}{ Patient 1} & \multicolumn{2}{|c|}{ Patient 2} \\
\hline & \multirow[b]{2}{*}{ Pre-treatment } & \multicolumn{3}{|c|}{ Post-treatment } & \multirow[b]{2}{*}{ Pre-treatment } & \multirow{2}{*}{$\begin{array}{c}\text { Post-treatment } \\
4 \text { mos }\end{array}$} \\
\hline & & 3 wks & $6 \mathrm{mos}$ & 18 mos & & \\
\hline \multicolumn{7}{|l|}{ Fibriliation* } \\
\hline Proximal muscles $\dagger$ & 1.0 & 0.8 & 0.4 & 0.3 & 0.7 & 0.2 \\
\hline Distal musclesł & 0.7 & 1.0 & 0.5 & 0.2 & 0.5 & 0.5 \\
\hline \multicolumn{7}{|l|}{ Recruitment§ } \\
\hline Proximal muscles & 2.5 & 3.0 & 4.0 & 4.0 & 3.8 & 4.0 \\
\hline Distal muscles & 2.3 & 3.0 & 4.0 & 4.0 & 4.0 & 4.0 \\
\hline \multicolumn{7}{|l|}{ Amplitude \| } \\
\hline Proximal muscles & 0.5 & 0.7 & 0.0 & 0.0 & 0.0 & 0.0 \\
\hline Distal muscles & 1.7 & 1.0 & 0.0 & 0.0 & 0.0 & 0.0 \\
\hline \multicolumn{7}{|l|}{ Polyphasiađ } \\
\hline Proximal muscies & 2.0 & 0.4 & 0.0 & 0.0 & 0.0 & 0.0 \\
\hline Distal muscles & 2.0 & 1.0 & 0.3 & 0.0 & 0.0 & 0.0 \\
\hline
\end{tabular}

*Fibrillation: $0=$ normal, $4=0 b$ scures baseline at every site

†Proximal muscies: paraspinal, triceps, biceps brachii, deltoid, vastus medialis, gluteus medius.

fDistal muscies: first dorsal interosseus of hand and foot, anterior tibialis, medial gastrocnemius, abductor hallucis

SRecruitment: $4=$ normal, $1=$ severely decreased motor unit recruitment.

1. Amplitude: $0=$ normal, $3=$ severely increased for particular muscle.

IPolyphasia: $0=$ normal, $3=$ severely increased number of phases and tums 
symptoms and reduction of WSR followed dosage increase to $20 \mathrm{mg} /$ day. After 3 weeks of treatment, when the patient was asymptomatic, repeat electromyographic studies were unchanged (Table 1). Repeated studies at 6 and 18 months disclosed reduced spontaneous activity with complex repetitive discharges present in paraspinal muscles only and near resolution of voluntary motor unit action potential abnormalities with mild changes persisting in distal limb muscles.

Case Presentation 2. PS is a 71 -year-old man with a 3-month history of bilateral knee swelling and pain, weakness and fatigue, poor appetite, and 15 lb weight loss. Seven months previously he ran a marathon race. There was restricted shoulder movement and atrophy of the deltoid muscles. Bilateral, nontender axillary adenopathy was palpable. Proximal muscle strength was difficult to assess because of shoulder pain, but he was unable to rise from a deep knee bend without assistance. Distal strength was normal.

Significant laboratory studies were WSR of 126 and a normochromic, normocytic anemia. Biopsy of an axillary lymph node showed reactive hyperplasia and histiocytosis. Biopsy of the vastus lateralis muscle showed atrophy of Type II fibers and to a lesser extent Type I fibers (Fig. 2). There were rare clumps of pyknotic nuclei but no inflammatory infiltrates. Temporal artery biopsy was unremarkable. Nerve conduction studies were normal except for reduced median sensory nerve evoked responses bilaterally. Concentric needle examination revealed fibrillation potentials in most distal and proximal limb muscles and complex repetitive discharges in paraspinal muscles only. Reduced recruitment of motor unit action potentials was noted in paraspinal and proximal limb muscles, and there were mild increases in the degree of polyphasia (Table 1).

Treatment with oral prednisone $(30 \mathrm{mg} /$ day $)$ resulted in dramatic reversal of his appetite, pain, and fatigue complaints. After 6 weeks, the patient was jogging several miles per day, objective strength testing was normal, and WSR and hematocrit were normal. Repeat electrodiagnostic studies 4 months later revealed nearly complete resolution of fibrillation potentials and voluntary motor unit action potential abnormalities (Table 1).

\section{DISCUSSION}

In most reviews of polymyalgia rheumatica, electrodiagnostic studies are described as normal, 2,7 but there are reports of spontaneous activity and abnormalities of motor unit recruitment. ${ }^{3,9,11}$ In some, interpretation of denervation is difficult because of evidence for concurrent polyneuropathies. In two cases of polymyalgia rheumatica with electromyographic abnormalities, both had distal polyneuropathy and one a superimposed mononeuritis multiplex. ${ }^{\text {I }}$ In another report, a patient with giant cell arteritis and polymyalgia rheumatica presented with a symmetric polyneuropathy

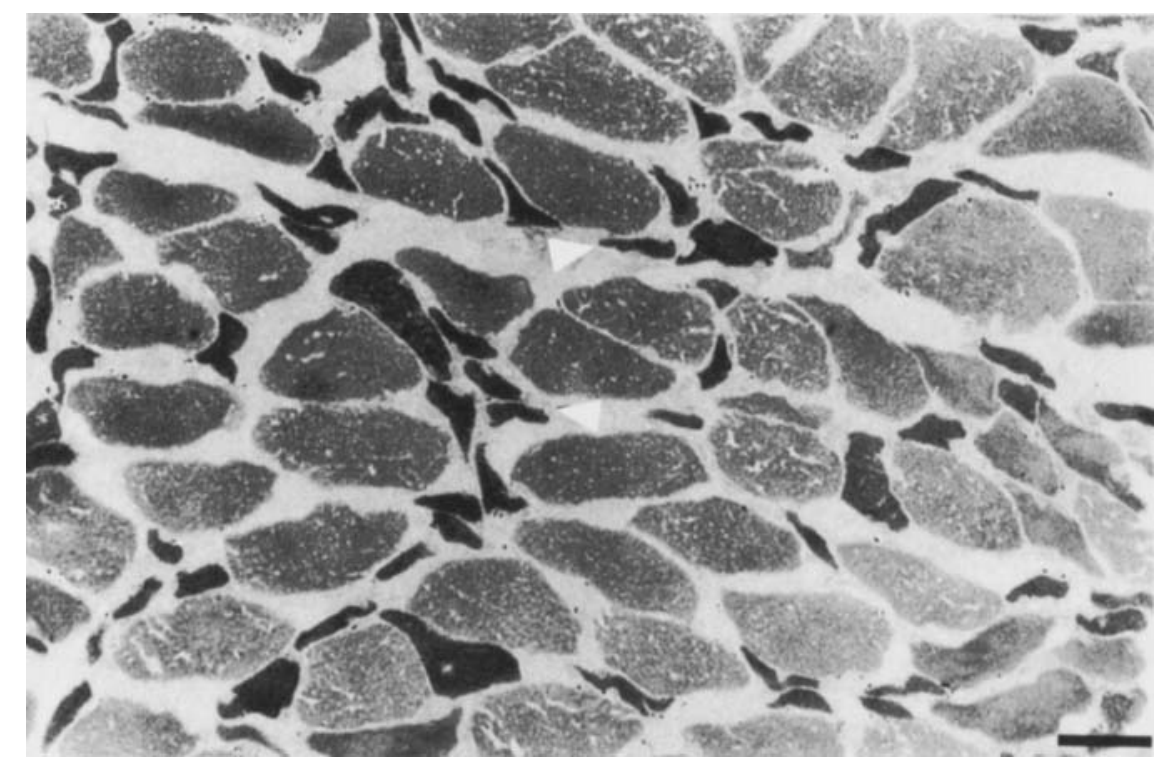

FIGURE 2. Vastus lateralis muscle biopsy. Tissue flash-frozen, sectioned on a cryostat, and stained with ATPase ( $\mathrm{pH}$ 9.4). Atrophic, angular fibers predominantly Type Il (arrowheads). Bar $=100 \mu \mathrm{m}$. 
and superimposed mononeuritis multiplex. Upper extremity nerve conduction studies normalized following prednisone treatment, yet lower extremity conduction abnormalities changed little. Crisp and Altman ${ }^{6}$ described a patient with polymyalgia rheumatica and vitiligo who experienced a rapid response to steroids but 9 months later developed proximal and distal weakness, pathologically brisk reflexes, and extensor plantar signs. Nerve conduction studies were normal, but electromyography disclosed chronic partial denervation, and muscle biopsy showed widespread atrophy. He subsequently expired from rapidly progressive weakness felt to be most consistent with motor neuron disease. The case most similar to ours is a 62-year-old woman with polymyalgia rheumatica who had resolution of symptoms and normalization of electrodiagnostic findings of fibrillation potentials in paraspinal and proximal muscles 6 weeks after prednisone therapy. ${ }^{9}$

Buchthal $^{3}$ performed quantitative motor unit action potential measurements in six patients with polymyalgia rheumatica and found evidence for myopathy based on a decrease in motor unit duration of more than $20 \%$ and a greater than $12 \%$ incidence of polyphasic potentials. Motor unit morphology, however, was judged normal on subjective assessment in these same patients.

The pathophysiology of polymyalgia rheumatica remains unknown. Thickened and inflamed synovium consistent with a synovitis has been identified in the sternoclavicular joints of four patients with polymyalgia rheumatica. ${ }^{2}$ Histochemical study of muscle revealed atrophy mainly of Type II fibers attributed to disuse of muscles adjacent to stiff and painful joints. ${ }^{1}$

A strong clinical association exists between polymyalgia rheumatica and giant cell arteritis, but a common pathophysiologic link has not been identified. Although vessel involvement in giant cell arteritis is primarily in the cerebral and cervical circulation, large and small vessels to other organs can be involved, ${ }^{4}$ suggesting that giant cell arteritis is a diffuse vasculitis both in distribution and vessel size. Recent reports describe peripheral nerve abnormalities in patients with polymyalgia rheumatica and giant cell arteritis and include polyradiculopathies, polyneuropathies, and mononeuropathies in up to $14 \%$ of patients. ${ }^{5,10}$ Many had improvement of their neuropathies with corticosteroid therapy. These authors considered an arteritis involving nutrient vessels or the vasa nervorum as possible pathologic mechanisms.

In our two patients the electromyographic abnormalities cannot be attributed to disease of the anterior horn cell, peripheral nerve, or neuromuscular junction. Any hypothesis for the spontaneous activity and neurogenic motor unit action potential abnormalities must also explain the impressive response to steroid therapy. We hypothesize a microvasculitis, possibly on an inflammatory basis, producing ischemia in the vasa nervorum. This ischemic process affecting motor nerve terminal branches through axonal involvement could produce scattered denervation and fibrillation potentials and a remodelling of the motor unit resulting in reduced motor unit recruitment and polyphasia. The rapid resolution of these electromyographic features after corticosteroid therapy is consistent with a reversible microvasculitis and reinnervation. Supporting evidence must await detailed light and electron microscopic examination of the intramuscular vasa nervorum.

\section{REFERENCES}

1. Brooke $\mathrm{MH}$, Kaplan H: Muscle pathology in rheumatoid arthritis, polymyalgia rheumatica, and polymyositis. Arch Pathol 1972;94:101-118.

2. Bruk MI: Articular and vascular manifestations of polymyalgia rheumatica. Ann Rheum Dis 1967;26:103-116.

3. Buchthal F: Electrophysiologic abnormalities in metabolic myopathies and neuropathies. Acta Neurol Scand (suppl) 1970;43:129-176.

4. Cardell BS, Hanley T: A fatal case of giant-cell or temporal arteritis. J Path Bact 1951;63:587-597.

5. Caselli RJ, Daube JR, Hunder GG, Whisnant JP: Peripheral neuropathic syndromes in biopsy-proven giant cell (temporal) arteritis. Neurology 1988;38:685-689.

6. Crisp AJ, Altman P, Ranger P: Vitiligo and motor neurone disease following acute polymyalgia rheumatica. $\mathrm{Br} J$ Clin Prac 1981;10:367-368.

7. Davison S, Spiera H, Plotz CM: Polymyalgia rheumatica Arth Rheum 1966;9:18-23.

8. Feigel DW, Robbins DL, Leek JC: Giant cell arteritis associated with mononeuritis multiplex and complementactivating $19 \mathrm{~S} \mathrm{IgM}$ rheumatoid factor. Am $J$ Med I $985 ; 79: 495-500$.

9. Gross MD, Borkin MH, Rupp S: Unusual electromyographic findings in a patient with polymyalgia rheumatica. Arth Rheum 1979;22:277-280.

10. Nesher G, Rosenberg P, Shorer Z, Galai A, Solomonovich $A$, Sonnenblick M: Involvement of the peripheral nervous system in temporal arteritis-polymyalgia rheumatica. Report of 3 cases and review of the literature. $J$ Rheumatol $1987 ; 14: 358-360$.

11. Warrell DA, Godfrey S, Olsen EGJ: Giant-cell arteritis with peripheral neuropathy. Lancet 1968;1:1010-1013. 